\title{
What will classrooms and schools look like in the new millennium?
}

\section{Elizabeth Birr Moje \\ University of Michigan, Ann Arbor, USA}

\section{Who will be in these classrooms?}

W e have witnessed vast change in the student population of schools and classrooms in the last 50 years. Because people can move easilyphysically and electronically-across state, national, and international boundaries, many of our schools, particularly in small but growing cities in the United States (e.g., Austin, Texas; Salt Lake City, Utah), are diverse in regard to ethnicity, social class, socioeconomic status, and language use. These trends in diversity of student populations will continue. Our teaching and administrative population will also become more diverse, although those changes will be slow. More dual-language speakers will enter the teaching work force because universities, administrators, and school boards someday will recognize the need for teachers to possess language skills that generate opportunities for all students to learn (cf. Valdés, 1998).
As diversity becomes a norm in our schools, we initially may see less and less tolerance for difference. Although I have observed kids of many colors and cultures "kickin' it," as they would say, I have also noted a focus on ethnicity and color that, when not framed by a critical perspective on difference and oppression, suggests divisiveness and intolerance, a struggle over material resources. My concern certainly is fueled by recent hate crimes committed by relatively young people throughout the world, but it is also sparked by the comments that I routinely hear from the people with whom I work, comments that highlight difference and that position some people as lacking (e.g., "Those Croatians almost seem white." "There's the ESL bus.").

Despite my concern for the attitudes regarding difference, I feel hope for the skills and knowledges that students will have in the future. Students of the future will possess different skills and ways of knowing the world, most of which will be shaped by their access to information technologies. While not all of these skills and knowledges will be positive, they will prepare youthperhaps more so than adults-to acknowledge the challenges of new times (cf. Luke \& Elkins, 1998).
Youth may have a better sense than adults about the changing landscapes of new times, even if they do not necessarily possess the requisite skills for taking on the challenges. We should listen to what kids are saying and watch what they're doing with their own time (cf. Alvermann, 1998) as we think about the changes in our schools and classrooms.

Even as I speculate that youth will have different and positive skills and knowledges, it is important to acknowledge issues of access: My daughter will grow up with a computer, but the youth with whom I work will only have access to a computer and the Internet if their schools, community centers, or libraries provide such access. They will have access to other equally influential media images and information devices, but the difference between being and not being online may be a deciding factor in the question of who has and who does not in our world of the future.

Another change that we may see in regard to the who of schools and classrooms revolves around parent and community involvement. As more and more parents and communities become dissatisfied with schools, we will see parent and community groups stepping forward to claim a voice in how their chil- 
dren are educated. Moll and Gonzalez (1994) detail a number of research projects in which parents and community organizations are an integral part of students' learning. While this change has great potential, particularly in regard to service learning opportunities for youth, it may also have negative potential if the parent and community groups who step forward are those who already possess privilege and power in social settings, and if they use their privilege and power to stamp down difference and to shut down possibilities for change.

\section{Why will we be teaching?}

In a changing world, one in which borders are shrinking as information flows unchallenged and unassessed across national and international boundaries, we must think carefully about our goals for literacy teaching. We should teach kids to read and write and hope that they can navigate a "complex, diverse, and sometimes dangerous world" (Commission on Adolescent Literacy, 1999). We must also teach youth how to use reading and writing to construct a just and democratic society. Unfortunately, as Bloome (in press) has argued, we do not have a clear vision of what it means to read and write in a just and democratic society. Literacy educators of the future need to construct a vision of reading and writing for democratic society and teach young people ways that they can participate in the construction of a society in which difference is valued and used in productive ways.

\section{What, how, and where will we teach?}

Because we will be striving to teach for a just and democratic society, we will need to broaden our sense of what it means to be literate, which suggests that in schools of the new millennium we will teach literacies. We will make more use of multiple forms of representation as alternative ways for students to make and communicate meaning (cf. Eisner, 1994). As we teach print literacy, we will want to draw from the different literacies that students bring to school learning (cf. Moje, in press). We will also need to teach youth about literacy practices, or the socially situated beliefs, values, purposes, and actions that shape how and why people use literacy. Thus, in addition to teaching cognitive processes, strategies, and skills of both traditional print literacies and the new literacies that are demanded by a changing world, we will also be teaching students to be metadiscursive so that they understand how different literacies and discourses are used to achieve particular purposes in particular social and cultural settings (cf. New London Group, 1996).

To accompany the teaching of new literacies and literacy practices, we will be using more project-based pedagogies (cf. Goldman, 1997;

Mercado, 1992) to teach our students different kinds of literacy skills such as the specialized information-gathering and navigating skills required for surfing and searching electronic learning technologies. These skills will be at the center of content learning, as the information associated with content (e.g., names and dates in history courses) takes a secondary position to the knowledge and skills necessary for accessing, synthesizing, and using such information. Even service positions in new times will require the sophistication of electronic searching and synthesizing skills, and businesses and industries will advocate for the teaching of such skills (Hull, 1998). Our teaching in the future will need to focus not just on such skills but also on the practices that accompany them. We will need to teach students to ask questions about whether and how these skills might be used to privilege some and oppress others.

Finally, service learning activities will be used as a way to take students' projects into the community so that students will learn both to navigate multiple discourse communities and to take action in the world outside of school. As more and more students at all achievement levels report feeling disconnected from the world in the confines of a school in which the learning seems contrived, community-based projects will increase motivation and reshape schools of the future.

\section{REFERENCES}

ALVERMANN, D.E. (1998). Imagining the possibilities. In D.E. Alvermann, K.A. Hinchman, D.W. Moore, S. Phelps, \& D. Waff (Eds.), Reconceptualizing adolescent literacies (pp. 353-372). New York: Erlbaum.

BLOOME, D. (in press). Boundaries on the construction of literacy in secondary classrooms: Envisioning reading and writing in a democratic and just society. In E.B. Moje \& D.G. O'Brien (Eds.), Constructions of literacy: Studies of literacy teaching and learning in secondary classrooms and schools. Mahwah, NJ: Erlbaum.

COMMISSION ON ADOLESCENT LITERACY. (1999). A position statement on adolescent literacy. Newark, DE: International Reading Association.

EISNER, E.W. (1994). Cognition and curriculum reconsidered (2nd ed.). New York: Teachers College Press.

GOLDMAN, S.R. (1997). Learning from text: Reflections on the past and suggestions for the future. Discourse Processes, 23, 357-398.

HULL, G. (1998). The changing world of work. Journal of Adolescent \& Adult Literacy, 42, 26-29.

LUKE, A., \& ELKINS, J. (1998). Reinventing literacy in "New Times." Journal of Adolescent \& Adult Literacy, 42, 4-7.

MERCADO, C. (1992). Researching research: A classroom-based student-teacher-researchers collaborative project. In A. Ambert \& M. Alvarez (Eds.), Puerto Rican children on the mainland: Interdisciplinary perspectives (pp. 167-192). New York: Garland.

MOJE, E.B. (in press). "To be part of the story": The literacy practices of "gangsta" adolescents. Teachers College Record.

MOLL, L.C., \& GONZALEZ, N. (1994). Lessons from research with language minority children. Journal of Reading Behavior, 26, 439-456.

NEW LONDON GROUP. (1996). A pedagogy of multiliteracies: Designing social futures. Harvard Educational Review, 66, 60-92.

VALDES, G. (1998). The world outside and inside schools: Language and immigrant children. Educational Researcher, 27(6), 4-18. 


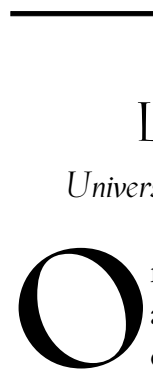

10

\section{Linda D. Labbo}

University of Georgia, Athens, USA

weather the following day would be "partly cloudy with unseasonably warm and spring-like temperatures." The following night he offered a sheepish apology to his faithful viewers who had been caught without coats and umbrellas when a cold front unexpectedly arrived much earlier than he had anticipated. "After all," he explained "the weather is a system of easily understood component parts, but the system is chaotic, driven by strong forces that subtly change how the component parts interact."

Predicting the future of literacy instruction has an even less likelihood of accuracy than does forecasting the weather. On one hand, predictions that are too ambitious tend to read like science fiction, a Brave New World (Huxley, 1950) that serves more as a cautionary tale of technology gone awry than as a vision of the future that ignites our collective imagination. On the other hand, predictions that are too modest tend to read like a mundane laundry list of potentialities that may be easily within our reach but are not especially desirable because they do not offer an inspiring vision or delineate an appropriate direction.

In attempting to make reasonable and informed predictions about what literacy instruction is likely to look like in the next millennium, I take under consideration a dynamic system that is sometimes as chaotic and unpredictable as the weather, the institution called school. Avoiding descriptions of an unreachable
Utopia that have no historical or pedagogical heritage, my educated guesses grow from speculation about the potential educational applications of technological developments that are emerging in other fields such as entertainment or business, and potential trends in technology-related educational professional development. I begin by describing three computer-related transformations for literacy teaching. The first transformation briefly recognizes the relationship between new digital genres and cognition. The second transformation begins to explore the role of new hardware and software design components in fostering supportive learning environments. The third transformation celebrates the potential of home-school digital connections. I close with a few comments about the teacher's role in future classrooms.

- New digital genres will promote transformed literacy learning and instruction. When viewed from a digital perspective, traditional conceptions of genre will be stretched to accommodate new discourse forms (e.g., e-mail, Web sites, games, simulations). Additionally, traditional notions of genre will be redefined through the electronic transformation of established discourse forms (e.g., picture storybooks accessed through interactive multimedia CD talking books; informational text presented in a hypermedia format). Underlying these reconceptualizations of genres as digital is the consideration of how reading on the computer is different from reading print. In the future, it will be clear that children engage in unique cognitive and motivational processes when meaning is digitally mediated through multimedia forms. It follows that literacy instruction will include helping students learn how to negotiate digital meaning by utilizing supportive features of software and by learning how to take a criti- cal, analytical stance to digitally mediated communicative forms.

- New hardware design compels transformed learning environments. Teachers of tomorrow, like teachers of yesterday, will take into consideration various social, psychological, motivational, pragmatic, and technological factors in creating and managing an appropriate learning environment. Creating an inviting classroom environment will be easy to accomplish because the classrooms themselves will be intelligent, inlaid with computers that are voice and touch sensitive. Affordable, thin computer monitor panels will hang on walls in place of chalkboards and will also serve as literal desk and table tops. The larger screens will enable teachers to demonstrate the forms and functions of multimedia digital literacy. For example, after dictating and discussing a morning message on a large wall screen, teachers may download individual copies onto each child's desktop screen to facilitate personal response activities.

In addition, previously incompatible or separately run computer applications (e.g., electronic books, word processors, art programs, video clips, e-mail) will converge to create cognitive learning digital tool kits that integrate the traditional language arts of speaking, listening, reading, and writing with the multimedia arts of animation, video, music, and art. An integral part of tool kits will consist of digitally animated agents or mentors that will be available on any computer screen a child might access in the school. Digital agents will be customized to offer each child guidance, support, and assistance in his or her efforts to use digital tools in the classroom.

- New digital applications foster transformed home-school connections. Home-school connections will be improved by what I will refer to as Optical Enablers, miniaturized 
digital video camera networks. For example, in some businesses employees, who are also parents of young children, have computers that are equipped with video camera connections that appear as a small window on their monitors. A click of the mouse at any time of the day allows them to check on their children who are enrolled in on-site day care programs. After parents access a sign-in screen that indicates their child's location, they are able to direct the angle of the camera to observe the child. This intranetwork technology, currently housed within one building, will expand to involve internetwork connections.

In the future all families will have affordable home computers that are as ubiquitous as telephones and televisions. As a result, parents from all walks of life will be able to digitally participate through Optical Enablers in the life of the classroom as storytellers, sources of information through interviews, or collaborators for other classroom projects.

Additionally, if a child must stay home due to an illness, he or she may digitally tune in to observe or interact during classroom activities. Digital conferences focusing on a child's progress may occur with the teacher sitting at a desk at school, the father sitting at a computer terminal at home, and the mother sitting at a computer terminal at work. Each monitor screen will display windows that show a portfolio of the student's work, run video clips of the child's oral reading, and offer relevant comments from the child's other teachers.

The brief comments offered in this article point to some intriguing possibilities for how computers may be integrated into literacy instruction and development in classrooms of the future. However, it should be noted that in the future, as it has been in the past, teachers will continue to be the key force that holds classroom literacy instruction together. Teachers will remain at the core of good literacy instruction because they are sensitive to children's needs and they understand how curriculum, materials, methods, and technology can harmoniously work together to offer a rich learning environment for students in the new millennium.

\section{REFERENCE}

HUXLEY, A. (1950). Brave new world. New York: Harper
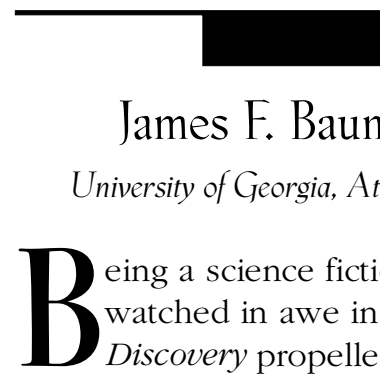

\section{James F. Baumann}

$$
\text { University of Georgia, Athens, USA }
$$

B eing a science fiction nut, I watched in awe in 1968 as Discovery propelled Dave Bowman, HAL, and the sleeping crew toward Jupiter in search of the secrets of the lunar monolith. I could hardly wait for the turn of the millennium to see if the future Arthur C. Clarke and Stanley Kubrick foretold in 2001: A Space Odyssey would be realized. What does our literacy odyssey beyond 2001 portend for classrooms and schools? Will there be exciting, innovative changes? Shocking, frightening ones?

Mundane ones?

As with any attempt at augury, one must fight both cynicism and Pollyannaism. Prognostication is dangerous business. 1984 (Orwell, 1949) came and went without drama; there (fortunately) was no Brave New World (Huxley, 1950); and Future Shock (Toffler, 1970) was, well, not quite so shocking. While perhaps not as dramatic as forecasting space or technology advances, projecting the nature of schools, classrooms, and students' literacy learning may be more crucial to our future global society. In this brief glimpse into the future, I've selectively identified three issues that I believe will persist, at least for a while, into the 21st century. Depending upon the nature of our literacy trek, their resolution may be worrisome or heartening. Student and teacher diversity. Projections indicate that while the United States school-age population will be increasingly more diverse (e.g., $74 \%$ white in 1980 vs. $55 \%$ white in 2020; America's Children, 1998), most teachers will remain mainstream (e.g., 91\% white teachers in 1996; Snyder, Hoffman, \& Geddes, 1997). Further, linguistic and academic diversity in classrooms is an increasing reality (e.g., $56 \%$ of teachers in a recent poll reported having students with limited English proficiency, and $79 \%$ reported having students with disabilities; Alexander, Heaviside, \& Farris, 1999). It is clear that teacher preparation institutions must be creative and aggressive in recruiting and retaining minority teachers and that pre- and inservice education must enable tomorrow's teachers to understand, communicate with, and accommodate our increasingly diverse school population. Our challenge is great on this issue, and the stakes are high. Current, heightened sensitivities to diversity and equity are encouraging, but time will tell whether and how we measure up.

Complex problems and simple solutions. I expect that simplistic solutions to complex literacy problems will continue to be offered by politicians, policy makers, and pundits while being credibly received by the populace. What the "No more social promotion," "Explicit, decontextualized phonics instruction across the grades," and "Technology is the answer" simple 
solutions of today will become tomorrow I know not, but I worry that they will be just as naive. A related concern is the continued deprofessionalization of teachers. Mandated assessments, legislated curriculum, and shackling policies can place teachers in a state of educational gridlock, denying them the opportunity to exercise professional judgment and pedagogical prerogative. It is our professional responsibility to challenge efforts to take teachers out of the decision-making process. We must fight the reduction of educational problems to one-dimensional solutions, but we must also offer viable, practical, complex alternatives. I believe we will be judged in the future on how assertive and courageous we are in arguing for sane policies in popular venues from defensible theoretical and empirical positions and-at least as important-communicating them along with practical solutions to educational decision makers.

Judicious literacy curriculum and instruction. Contrary to common public opinion, teachers have not engaged in dramatic pendulum swings in philosophy and practice. For example, rather than polarizing on the issue of holistic versus codeemphasis instruction, a significant majority of elementary teachers (89\%) indicated recently that they "believe $\{\mathrm{d}\}$ in a balanced approach to reading instruction which combines skills development with literature and language-rich activities" (Baumann, Hoffman, Moon, \& Duffy-Hester, 1998, p. 642). Due to the pragmatic nature of their work, teachers instead typically adopted a philosophy of disciplined eclecticism (p. 647), in which they selected, adapted, and employed an array of instructional materials and perspectives to accommodate the diverse needs of their students. I find this trend heartening, reassuring, and flexible enough to serve educators well in the next century. I just hope that we provide sufficient advocacy to enable teachers to make informed educational decisions.

Arthur C. Clarke stepped back into the future of humankind in 2010 (1982) and 2061 (1987), and he concluded his quartet in 3001 (1997) with these haunting words by the unnamed power behind the monolith: "Their little universe is very young, and its god is still a child. But it is too soon to judge them; when We return in the Last Days, We will consider what should be saved" (p. 237). Contrary to Clarke's rendering of the future, I believe our fate to be in our own hands. But I do consider him correct in determining it is too soon to judge. The nature of future classrooms and schools is up to us and will be decided long before the third millennium. I only hope that our literacy legacy will be worth saving.

\section{REFERENCES}

ALEXANDER, D., HEAVISIDE, S., \& FARRIS, E. (1999). Status of education reform in public elementary and secondary schools: Teachers' perspectives. Washington, DC: U.S. Department of Education.

America's children: Key national indicators of well-being. (1998). Washington, DC: Federal Interagency Forum on Child and Family Statistics. BAUMANN, J.F., HOFFMAN, J.F., MOON, J., \& DUFFY-HESTER, A.M. (1998). Where are teachers' voices in the phonics/whole language debate? Results from a survey of U.S. elementary teachers. The Reading Teacher, 51, 636-650.

CLARKE, A.C., WITH KUBRICK, S. (1968). 2001: A space odyssey. New York: New American Library.

CLARKE, A.C. (1982). 2010: Odyssey two.

New York: Ballantine Books.

CLARKE, A.C. (1987). 2061: Odyssey three.

New York: Ballantine Books.

CLARKE, A.C. (1997). 3001: The final

odyssey. New York: Ballantine Books.

HUXLEY, A. (1950). Brave new world. New York: Harper.

ORWELL, G. (1949). 1984. New York:

Harcourt, Brace.

SNYDER, T.D., HOFFMAN, C.M., \& GEDDES,

C.M. (1997). Digest of education statistics 1997.

Washington, DC: U.S. Department of Education.

TOFFLER, A. (1970). Future shock. New York: Random House.

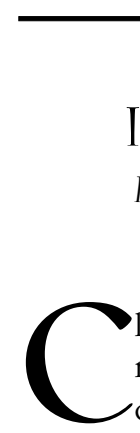

Irene W. Gaskins

Benchmark School, Media, Pennsylvania, USA

20th century. Buildings will have new, impressive configurations, technological innovations will abound, and the materials available to students and teachers will be more captivating than ever before. However, it may not be in such settings that we see the highest achievement in literacy. Dollars poured into buildings and contents, without the ingredients we now know are essential for literacy success, will not have the desired impact on improving literacy. What will make the difference in literacy achievement will be the same ingredients that have always made the difference-families and communities that value and support education and school cultures that foster nurturing relationships, professional growth of staff, and development of a research-based curriculum.

Tremendous promise for the 21 st century lies in the rich foundation of theory and research in literacy and child development amassed during the 20th century. It is a promise that will be fulfilled only by the careful selection, preparation, and support of principals who are literacy instructional leaders and of teachers and support staff who care about children and want to grow professionally. Successful schools of the next millennium will be places where staff are given more time for planning, collaborating, and learning than in the past and where staff will be engaged in ongoing evaluation and reshaping of curriculum and instruction to meet the needs of a diverse student population. In the 
most successful new millennium schools, the first priority for financial resources will be investments in people-in administrators and teachers who set and achieve the standard that all children will leave school with the literacy skills they need to participate in the political and economic mainstream.

In this essay I focus on nine research-based and theoretical maxims that will undergird the development of successful school cultures for literacy instruction in the next millennium. These maxims will be the focus of intensive staff development and curriculum revision in schools where student achievement in literacy meets high standards and apprenticeship of novice teachers to master teachers is the norm.

\section{There is no panacea.}

Educators will finally acknowledge that there are no best methods, materials, or technological innovations for teaching literacy. There is only good pedagogy. This pedagogy will be based on applying what we know about child development and learning to establish caring, supportive relationships with students.

\section{Literacy and learning pro-} ceed in a developmental progression. Those who teach literacy will understand that developmental timetables differ among children who are the same age, just as they differ between age groups. In addition, they will observe that each student has his or her own unique pattern of relative strengths. In view of these developmental differences, teachers and support staff will guide students in developing processes and abilities appropriate for their developmental levels. All students in a class will not be on the same page, or even in the same materials, but rather will be grouped, and regrouped, for specific tasks according to where they can function comfortably with teacher assistance. By providing scaffolding for students at levels where they can function successfully with teacher assistance, developmental differences will be respected in schools of the new millennium.

\section{Learning to read and write is} the result of a complex interaction between intrinsic and extrinsic factors. Educators will acknowledge that success, or difficulty, in learning to read and write is the result of what goes on inside a student's head, as well as what goes on in the classroom, home, and larger social contexts. These interactions are complex, not subject to simple cause-and-effect explanations. Thus, when a child is struggling, educators in the new millennium will not wait for someone to evaluate the child and suggest the etiology of the problem; rather, they will focus on diagnostic teaching to discover what works in teaching this struggling reader or writer. Where students are most successful in learning to read and write, teachers will have helped these students shape the many factors affecting learning rather than have documented their absence or inadequacy.

4. Students learn and persist where teaching practices rest on an understanding of motivational theo$r y$. In successful literacy classrooms practices will reflect the teacher's awareness that needs related to physiology, safety, belonging, and self-esteem must be met before students will be interested in how they can meet their needs for knowledge, appreciation, and fulfillment. Once basic needs are met, teachers will establish classroom cultures where students develop collaborative relationships, feel competent, make choices, and understand the rationale for strategies and concepts that they are expected to learn.

\section{Students learn what teachers} teach, and sometimes not a whole lot more. Teachers in the successful literacy classrooms of the new millennium will teach explicitly and well a few generative strategies and concepts over an extended period of time. They will provide explicit explanations and scaffolding for word learning, meaning making, and written expression, especially for struggling readers and writers. And, they will teach in a manner that is meaningful for their population of students.

6. Student involvement is crucial. Teachers will plan every-pupilresponse and collaborative activities that reflect their understanding that attentive, active, and reflective minds are necessary for learning. They will explain to students the rationale for attention, active involvement, and reflection. They will also provide students with frameworks for active engagement with knowledge and tasks and teach strategies for implementing each part of the framework.

7. Transactional discourse affects what is learned. Educators in the new millennium will value teacher-students and student-student discourse. They will employ a responsive and transactional discourse pattern, avoiding the pattern in which the teacher initiates, student responds, and teacher evaluates. They will balance teacher-student talk by involving students in teacher explanations and modeling, by encouraging requests for clarification and feedback, and by co-constructing goals, strategies, and understandings with students. They will provide frequent opportunities for students to experience purposeful transactional sharing and negotiating with other readers, writers, and learners.

8. Ample opportunities will be provided for meaningful practice. Classrooms in the new millennium will be filled with students engaged in meaningful reading and writing at their appropriate developmental levels. Some of this practice will be teacher assisted, and some will be self-regulated and independent. All of the practice will be on tasks documented to improve literacy and learning. 
9. Students will seek and apply specific knowledge. Knowledge will continue to change rapidly in the new millennium, thus the accumulation of knowledge that soon may be outdated will not be as valued as the ability to locate, evaluate, and apply information. Thus, students will be taught how to monitor what they know and do not know and how to locate the information they need, as well as how to manage choices, take different perspectives, and think critically. In classrooms where timely knowledge is valued, they will also learn that developing collaborative relationships, working well with others, and improving one's self for the good of the group will be important to their success.
Classrooms and schools of the new millennium will be multidimensional. No method or set of materials, no political stance or publisher will prevail. Instead, best practices, as outlined above, will set the course for what successful schools and classrooms look like in the new millennium. 